Int. J. Electrochem. Sci., 13 (2018) 1921 - 1930

\title{
Preparation of $\mathrm{LiTi}_{2} \mathrm{O}_{4}$ as a Lithium-ion Battery Anode by a Carbon-thermal Reduction Method
}

\author{
Jiang Zhao ${ }^{1,2, *}$, Qingling Shi ${ }^{1}$, Yangjun Xiang ${ }^{1}$, Yuanyuan Xia ${ }^{1}$ \\ ${ }^{1}$ Jiangsu Provincial Engineering Laboratory for RF Integration and Micropackaging, College of \\ Electronic Science and Engineering, Nanjing University of Posts and Telecommunications, Nanjing \\ 210023, P. R. China \\ ${ }^{2}$ School of Chemistry \& Chemical Engineering, Nanjing University, Nanjing 210023, P. R. China \\ *E-mail: jzhao_njupt@126.com
}

doi: $10.20964 / 2018.02 .33$

Received: 27 June 2017 / Accepted: 7 November 2017 / Published: 28 December 2017

The anode material $\mathrm{LiTi}_{2} \mathrm{O}_{4}$ was successfully synthesized by a carbon-thermal reduction method. The standard Gibbs free energy of formation of $\mathrm{LiTi}_{2} \mathrm{O}_{4}$ is estimated by bond enthalpy, and the thermodynamics of the carbon-thermal reaction are calculated. The microstructure of the $\mathrm{LiTi}_{2} \mathrm{O}_{4}$ sample is obtained by scanning electron microscope (SEM) and X-ray diffraction (XRD). The results show that the as-prepared $\mathrm{LiTi}_{2} \mathrm{O}_{4}$ has a spinel structure (space group $\mathrm{Fd} 3 \mathrm{~m}$ ) and that the average particle size is approximately $0.4-1.2 \mu \mathrm{m}$. $\mathrm{LiTi}_{2} \mathrm{O}_{4}$ shows excellent electrochemical performance in terms of galvanostatic charge/discharge tests, specific capacity and cycling performance. Electrochemical measurements indicate that the symmetrical redox peaks are observed at approximately $1.52 \mathrm{~V}$, and the reversible capacity is approximately $135.9 \mathrm{mAh} / \mathrm{g}$ at a rate of $0.2 \mathrm{C}$.

Keywords: Thermodynamics calculation; $\mathrm{LiTi}_{2} \mathrm{O}_{4}$; Carbon-thermal reduction; Lithium-ion battery

\section{FULL TEXT}

(C) 2018 The Authors. Published by ESG (www.electrochemsci.org). This article is an open access article distributed under the terms and conditions of the Creative Commons Attribution license (http://creativecommons.org/licenses/by/4.0/). 